\title{
Social and Clinical Impact of Congenital Urological Malformations in a Developing Country: The Need for a Transdisciplinary Way of Treatment
}

\section{Impacto social y clínico de las malformaciones urológicas congénitas en un país en desarrollo: La necesidad de un tratamiento transdisciplinario} \author{
Carolina Acevedo ${ }^{5}$ Ignacio Zarante ${ }^{6}$

\footnotetext{
1 Division of Urology, Department of Basic Science, Pontificia Universidad Javeriana, Hospital Universitario San Ignacio, Bogotá, Colombia

2 Department of Clinical Urology, University of Toronto, Hospital for Sick Kids, Toronto, ON, Canada

${ }^{3}$ General Physician, Pontificia Universidad Javeriana, Bogotá, Colombia

${ }^{4}$ Medical Student, Pontificia Universidad Javeriana, Bogotá, Colombia

${ }^{5}$ Bogotá District Health Secretariat, Programa de Vigilancia de

Malformaciones Congénitas de la Ciudad de Bogotá, Bogotá, Colombia

6 Human Genetics Institute, Pontificia Universidad Javeriana, Bogotá, Colombia
}

Nicolás Fernández ${ }^{1,2}$ Angie Puerto Niño ${ }^{3} \quad$ Dan Jaim Arreaza Kaufman ${ }^{4}$ Gloria Gracia $^{5}$ Lina Ibañez ${ }^{5}$

Urol Colomb 2019;28:285-290.

\author{
Address for correspondence Angie Puerto Niño, MD, Pontificia \\ Universidad Javeriana, Bogotá, Colombia \\ (e-mail: puertoa@javeriana.edu.co; apuertonino@gmail.com).
}

\begin{abstract}
Keywords

- congenital anomalies

- congenital urological anomalies

- health care system

- urogenital tract

- pediatric urology

Introduction The prognosis of congenital anomalies (CAs) can be improved if detected and treated accurately. Given the complexity of some anomalies, it is almost always necessary to approach them with an interdisciplinary team. Our objective was to contact patients with congenital urological anomalies (CUAs) and follow them up during their first years of life and evaluate their clinical status, as well as their social and health care limitations. Method Based on the Bogota Congenital Malformations Surveillance Program (BCMSP), we have contacted by phone all the patients with CUAs and evaluated their follow-up. We have included all the registered patients from 2006 until 2015. A standardized questionnaire was applied by a trained staff. The questions assessed on each call included: evaluation of the clinical status of the patient, the clinical treatments and evaluations performed by clinical and surgical subspecialties, health care limitations, and social barriers. The first call was made at the 2 nd month, then every 3 months during the 1st year and every 6 months thereafter.

Results A total of 277 patients were contacted, $97.3 \%$ of whom have an increased risk of mortality or significant disability. The malformation related mortality was of $38.1 \%$. Only $38.7 \%$ of the patients were evaluated by a specialist, while $57.4 \%$ where still waiting to be seen by a specialist. Ninety eight percent of the limitations related to the health care system were the long waiting lists to be seen by a specialist.
\end{abstract}

received

April 2, 2018

accepted

April 6, 2018
DOI https://doi.org/

$10.1055 / \mathrm{s}-0038-1668110$.

ISSN 0120-789X.

e ISSN 2027-0119.
Copyright ( 2019 , Sociedad Colombiana License terms de Urología. Publicado por Thieme Revinter Publicações Ltda., Rio de Janeiro, Brazil. Todos los derechos reservados.

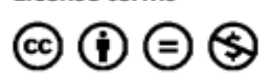




\section{Resumen}

\section{Palabras Clave}

- anomalías congénitas

- anomalías congénitas urológicas

- sistema de salud

- tracto urogenital

- urología pediátrica
Conclusion Many of the pathologies that we have found belong to the group that has a significant reduction in mortality when treated accurately and promptly. However, we have a profound problem in our health care system, in that many of the patients have not been seen by a specialist, which results in a worse prognosis and recovery rate.

Introducción El pronóstico de las anomalías congénitas puede mejorarse si se detectan y tratan adecuadamente. Dada la complejidad de algunas anomalías, casi siempre es necesario abordarlas con un equipo interdisciplinario. Nuestro objetivo fue contactar a los pacientes con anomalías urológicas congénitas (CUA) con posterior seguimiento durante los primeros años de vida, se evaluó su estado clínico así como las limitaciones sociales y de atención médica.

Método Basado en el Programa de Vigilancia de Malformaciones congénitas de Bogotá, contactamos por teléfono a todos los pacientes con CUA y evaluamos su seguimiento. Fueron incluidos todos los pacientes desde 2006 hasta 2015. Un cuestionario estandarizado fue aplicado por personal capacitado. Las preguntas evaluadas durante la llamada incluyeron: evaluación del estado clínico, tratamientos clínicos realizados y evaluaciones por subespecialidades clínicas y quirúrgicas, limitaciones de atención médica y barreras sociales. La primera llamada se realizó en el segundo mes y luego cada tres meses durante el primer año y luego cada 6 meses a partir de entonces.

Resultados Se contactó a un total de 277 pacientes en los que el 97,3\% tenía un riesgo de mortalidad o de discapacidad significativa. La mortalidad relacionada con la malformación fue del $38.1 \%$. Solo el $38,7 \%$ de los pacientes fueron evaluados por un especialista, mientras que el $57,4 \%$ aún esperaban ser atendidos por un especialista. El noventa y ocho por ciento de las limitaciones relacionadas con el sistema de atención fueron las largas listas de espera para ser visto por un especialista.

Conclusión Muchas de las patologías pertenecen al grupo que cuando son tratadas adecuadamente y prontamente tienen una reducción significativa en la mortalidad. Sin embargo, tenemos un problema profundo en nuestro sistema de atención médica donde muchos de los pacientes no han sido atendidos por un especialista, lo que resulta en un peor pronóstico y tasa de recuperación.

\section{Introduction}

Congenital anomalies (CAs) are the leading cause of death and morbidity in children. ${ }^{1}$ An appropriate detection and prompt treatment are essential to reduce complications in these children. Multiple approaches have been made to better identify and study CAs. The models of surveillance systems and case-control studies have shown the best results to evaluate this kind of patients. ${ }^{2}$ Most of the congenital urological anomalies (CUAs) belong to the group of malformations that have a significant reduction in future disability and even in mortality when detected and treated properly, which is a cost-effective measure. ${ }^{3}$

A vast amount of information is known about the natural history and complications of the patients with CUAs and spina bifida (SB). ${ }^{4,5}$ We need further studies to know what happens with children with CAs that are born in developing countries, where the access to health care and specialists is limited. In Africa, given the limited resources and trained personnel, the detection rate of CAs by ultrasound is around 5.9\%, compared to data from developed countries, where the detection rates are significantly higher, reaching $30 \%$ or even more. ${ }^{6,7}$

In our population, we have identified a prevalence rate of CUAs of 4.3 cases per 10,000 newborns and, after a 2-year follow-up, we have identified that $22 \%$ of the patients require a surgical procedure to improve their current clinical status, but most of them had not been seen by a specialist and were never approached by an interdisciplinary team. ${ }^{8}$ We now want to establish a longer prospective follow-up of patients with CUAs.

\section{Methodology}

\section{Database}

The analysis of the data was based on the Bogota Congenital Malformations Surveillance Program (BCMSP). This is a program that was established in 2006, in which all hospitals in the city of Bogota participate registering data of newborns with CAs. This program is governed by the department of health of the city of Bogotá with the support of the Human Genetics Institute at the Pontificia Universidad Javeriana. On a daily 
basis, all newborns at each hospital are examined in search of a detectable CA at birth. Once a malformed newborn is identified, it is registered in the database for analysis. Data registration follows two modalities: The Public Health Surveillance System (SIVIGILA, in the Spanish acronym), which includes demographic data of the mother and the newborn, as well as a description of the anomaly or anomalies. The other is the casecontrol model, in which the same information is included, as well as more details about prenatal medications, ultrasounds, medical and family history of the mother, the socioeconomic status of the parents and the highest level of education reached by the mother. For both modalities, a follow-up program was established with a trained staff of the Human Genetics Institute. After the cases were discharged from the hospital, we performed a standardized follow-up by phone of all cases with a risk of developing complications directly related with the anomaly according to the prognostic scale developed in our institution and described by Zarante et al. ${ }^{9}$ The 1 st call was made at the 2nd month, and then every 3 months during the 1 st year, and every 6 months thereafter.

For the purpose of the present study, we have only included cases with CAs affecting the urinary tract, the genitals and also spina bifida (SB), given their clinical implications for the urologic practice.

\section{Follow-up}

For all cases included in both modalities, a telephonic followup was performed. Our staff was previously trained, and all mothers and their babies were evaluated on a standardized fashion. For cases that had specific complications or issues with the health care access, a face-to-face interview was scheduled, in which the same questionnaire was repeated, and the patients were referred to a specialist.

The follow-up questions included an initial confirmation of the diagnosis and whether the patient was alive or not. If the patient was alive, the next question was about the perception of the caregiver regarding the current health of the patient. This was a free text answer. If the patient had died, the next question was about the cause of death. The following questions included the surgical procedures undergone by the patient, which specialties saw him (we did not consider general pediatrics as a subspecialty). The questionnaire also addressed if the patient had any complications related to the malformation and or the surgery. The remaining questions included affiliation to the health system, limitations of the health system and, finally, the limitations of the family or of the caregiver.

\section{Data Analysis}

The information was digitalized using Microsoft Excel 2013 (Microsoft Corporation, Redmond, WA, USA), and the frequency distributions of the demographic variables were calculated.

\section{Results}

Between January 2006 and December 2015, a total of 420,268 births were registered. Out of this total, we have identified 393 patients with CUAs ( - Table 1). At birth, 99(25.2\%) of the cases were registered as female, 10 (2.5\%) as indeterminate gender,
Table 1 Description of detected congenital urinary anomalies and their classification according to the prognosis at birth and impact after treatment

\begin{tabular}{|c|c|c|c|c|}
\hline Malformation & IIb & IIIb & IIId & Total \\
\hline Hydronephrosis & 105 & & & 105 \\
\hline Hypospadias & 76 & & & 76 \\
\hline Spina bifida & 53 & & & 53 \\
\hline Cryptorchidism & 47 & & & 47 \\
\hline Disorder of sex development & 33 & & & 33 \\
\hline Multicystic dysplastic kidney & 14 & & & 14 \\
\hline Renal agenesis & 13 & & & 13 \\
\hline Polycystic kidney disease & 11 & & & 11 \\
\hline \multicolumn{2}{|l|}{ Micropenis } & & 6 & 6 \\
\hline Eagle-Barrett syndrome & 5 & & & 5 \\
\hline Hydrocele & 5 & & & 5 \\
\hline Imperforated anus & 4 & & & 4 \\
\hline Clitoromegaly & 4 & & & 4 \\
\hline \multicolumn{3}{|l|}{ Chordee } & 2 & 2 \\
\hline Congenital adrenal hyperplasia & 2 & & & 2 \\
\hline \multicolumn{3}{|l|}{ Ectopic kidney } & 2 & 2 \\
\hline Tuberous sclerosis & 2 & & & 2 \\
\hline Penoscrotal transposition & 2 & & & 2 \\
\hline Posterior urethral valves & 1 & & & 1 \\
\hline Inguinal hernia & 1 & & & 1 \\
\hline Megaureter & 1 & & & 1 \\
\hline Epispadias & 1 & & & 1 \\
\hline Ureteral duplication & 1 & & & 1 \\
\hline Renal hypoplasia & & 1 & & 1 \\
\hline Tubular acidosis & 1 & & & 1 \\
\hline TOTAL & 382 & 1 & 10 & 393 \\
\hline
\end{tabular}

and $284(72.3 \%)$ as male. When specifically analyzing the 10 cases assigned initially as indeterminate, we have found that 7 had an initial diagnosis of disorder of sex development (DSD) and the remaining 3 were: a case with Eagle-Barret syndrome, one with hypospadias and one with hydronephrosis. The gender of the patients was changed from indeterminate to male in three cases and to female in two. The remaining could not be contacted at the follow-up.

According to the previously described prognostic scale, ${ }^{9}$ 97.3\% of the cases belong to the group of CAs with an increased risk of mortality and/or significant disability (group II in -Table 1). However, if treated appropriately, the risk of future disability is significantly reduced (group b in - Table 1). The remaining anomalies belong to the group of patients with CAs whose birth defects do not have a significant impact on their prognosis.

At the follow-up, we were able to contact 277 (70.5\%) of the cases. Of those who answered the phone call, 230 (83\%) completed the questionnaire, 26 (9.4\%) had a wrong number 
registered and were not interviewed. Twenty-one (7.6\%) had died before the call was made. In 8 (38.1\%) cases, the cause of death was due to the malformation itself. Three (14.6\%) cases died due to an infection, and the remaining causes were indirectly related with the anomaly.

On average, the first call was made at an age of 198 days after birth ( \pm 378.5 days). In $81.8 \%$ of the cases, the caregiver of the patient was the mother, followed by the father in $7.3 \%$ and the grandmother in $4.5 \%$. The remaining caregivers were close relatives. On average, the caregivers spend 20.3 hours ( \pm 4.8 hours) a day taking care of their children.

When asked about the CA during the interview, 19 cases (6.8\%) stated that the initial diagnosis had been discarded. Of these, 12 (63.1\%) were initially diagnosed as hydronephrosis, which had been resolved at the time of the follow-up. One case with cryptorchidism had been resolved, as well as a case of hydrocele. Four cases with an initial diagnosis of a DSD were ruled out at the follow-up. The caregivers explained to the interviewers that the reason for this change was the prematurity of the patient. A case of SB was ruled out after a magnetic resonance imaging (MRI) exam.

All of the cases, except for one, were affiliated to the health system at the moment of the interview. Subjectively, $83.4 \%$ of the caregivers had a positive perception of the clinical status of the condition of the newborn. The remaining did not have a positive impression due to direct complications of the CA or due to issues after the surgical repair. When asked if the patients had been seen by a specialist, 97 (38.7\%) had been, 86 (34.3\%) had not been evaluated at the moment of the call and $58(23.1 \%)$ were waiting to be seen. The most common visited specialty was urology (30\%), followed by neurosurgery $(20 \%)$ and nephrology (19\%). The remaining specialties were pediatric surgery (12\%), neurology (7\%), endocrinology (5\%), and genetics (4\%). Only 18 (7\%) of the followed cases had been seen by 2 different specialties, and none by more than 2 . No multidisciplinary approach was performed on these patients. None of the DSD cases had been seen in a reference center by a multidisciplinary group. Not all of the SB patients had been seen by a neurosurgeon. As shown on - Table 2, during the first year of life, from the total of 100 patients that had been seen by a specialist, $47 \%$ of these consultations were for the top 5 anomalies. - Fig. 1 shows the proportion of patients that had or had not been seen by a specialist or were waiting to be seen during the first 10 months after birth (no visits were registered during months 11 and 12 ).

When evaluating the health system issues and the limitations of the family, 16 (6.4\%) patients had issues with the affiliation to the system (Colombia is supposed to have a universal coverage system). The most common limitations that the caregivers had to deal with concerning the health care of their babies were lack of economic resources, poor knowledge about the disease, and the third cause was human forced displacement. When evaluating if the limitations originated from issues concerning the caregiver, we found that $91.3 \%$ of the caregivers were favorable and interested in the health of their babies.

When evaluating the issues related to the access to the health care system, we found that $98.01 \%$ of the limitations were because the service was authorized but the schedule to be seen by a specialist or to get access to any other service or medical supplies or special treatments took months before it happened. The average waiting list was of 6 months.

\section{Discussion}

When treated properly and by trained personnel, CUAs have significantly reduced disability and mortality rates. In our population, a significant amount of cases have limited access to health care specialists, which results in important repercussions in the health and prognosis of the patients. Although more than $90 \%$ of the cases were affiliated and insured, this does not guarantee a proper evaluation and treatment. We have found that many of the malformations

Table 2 Description of the follow-up of the top 5 congenital urinary anomaly patients during their first year of life

\begin{tabular}{|l|l|l|l|l|l|}
\hline Month & $\begin{array}{l}\text { Hydronephrosis } \\
\text { Followed (Total) }\end{array}$ & $\begin{array}{l}\text { Hypospadias } \\
\text { Followed (Total) }\end{array}$ & $\begin{array}{l}\text { Spina Bifida } \\
\text { Followed (Total) }\end{array}$ & $\begin{array}{l}\text { Cryptorchidism } \\
\text { Followed (Total) }\end{array}$ & $\begin{array}{l}\text { DSD } \\
\text { Followed (Total) }\end{array}$ \\
\hline 1 & $1(105)$ & $1(76)$ & $17(53)$ & $1(47)$ & $0(33)$ \\
\hline 2 & $3(105)$ & $1(76)$ & $2(53)$ & $0(47)$ & $0(33)$ \\
\hline 3 & $1(105)$ & $1(76)$ & $0(53)$ & $0(47)$ & $1(33)$ \\
\hline 4 & $0(105)$ & $0(76)$ & $1(53)$ & $0(47)$ & $0(33)$ \\
\hline 5 & $0(105)$ & $0(76)$ & $0(53)$ & $0(47)$ & $0(33)$ \\
\hline 6 & $0(105)$ & $0(76)$ & $0(53)$ & $0(47)$ & $0(33)$ \\
\hline 7 & $0(105)$ & $7(76)$ & $0(53)$ & $0(47)$ & $0(33)$ \\
\hline 8 & $0(105)$ & $0(76)$ & $0(53)$ & $0(47)$ & $0(33)$ \\
\hline 9 & $2(105)$ & $2(76$ & $0(53)$ & $0(47)$ & $0(33)$ \\
\hline 10 & $0(105)$ & $0(76)$ & $0(53)$ & $0(47)$ & $0(33)$ \\
\hline 11 & $3(105)$ & $1(76)$ & $0(53)$ & $0(47)$ & $0(33)$ \\
\hline 12 & $1(105)$ & $0(76)$ & $0(53)$ & $0(47)$ & $1(33)$ \\
\hline TOTAL & $11(105)$ & $13(76)$ & $20(53)$ & $1(47)$ & $2(33)$ \\
\hline
\end{tabular}

Abbreviations: DSD, disorder of sex development. 


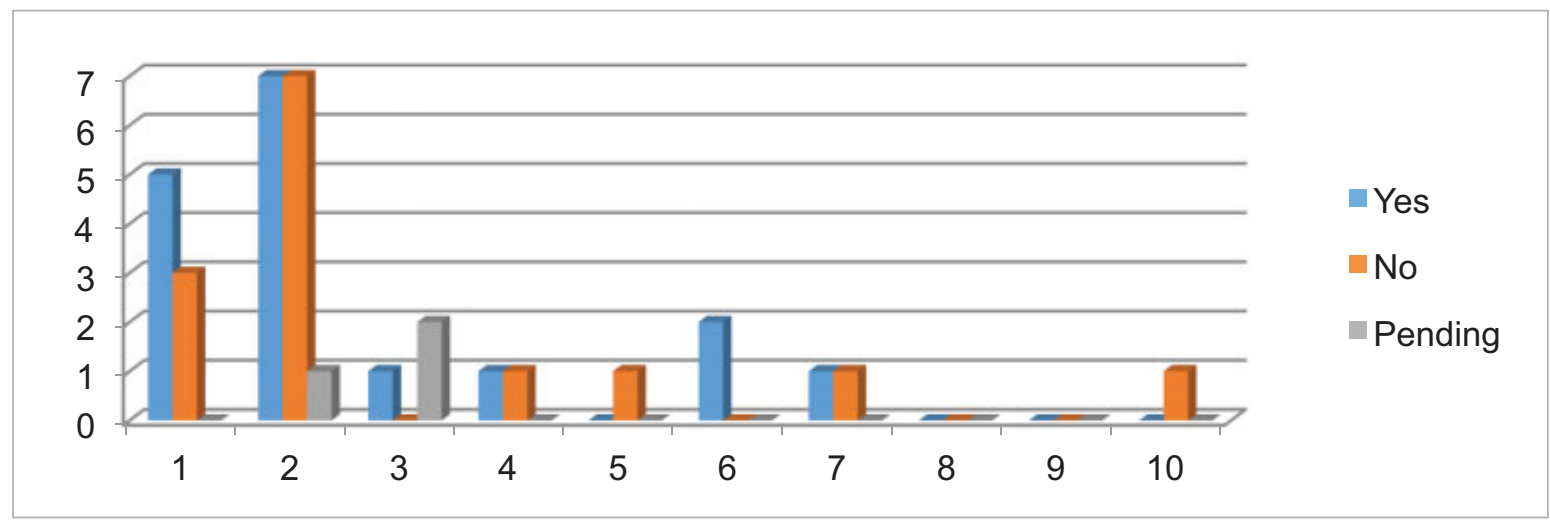

Fig. 1 Description of evaluated patients by any specialist during the first year of life.

that affect our patients belong to the group of CAs with an increased risk of mortality and/or significant disability. ${ }^{9}$ However, due to the fact that $57.4 \%$ of the patients had not been seen by a specialist by the time of our first call, we ought to assume that there is a problem in the way these patients are being handled and referred. For example, conditions such as severe hydronephrosis, posterior urethral valves, and saltlosing congenital adrenal hyperplasia, whose prognosis depends on the prompt detection and treatment, need to be evaluated accurately. ${ }^{10,11}$ It has been considered that no visible anomalies at birth might reduce the chance of not being properly detected. Nonetheless, this argument is difficult to consider after identifying that only $20 \%$ of the patients with SB had not been seen by a neurosurgeon at the time of the first call. The same was seen with patients with DSDs and hypospadias. ${ }^{12}$

According to the recommendations from the American Academy of Pediatrics (AAP), the surgical correction of the patients with hypospadias should be performed before the age of 18 months. Therefore, the diagnosis of these patients must be made at an early age for them to have a proper surgical treatment. ${ }^{13}$ According to our results, this is far from ideal.

Another key issue that our patients face is that none had been seen by more than one specialist. Due to the complexity of CAs, it is important to establish that these patients benefit and have to be seen by transdisciplinary teams that assess and treat them. ${ }^{14}$ For a developing country, costs are important, and the budget needs to be well spent. Transdisciplinary teams have demonstrated to be cost-effective. Well trained personnel, more experience, and a high volume of patients are factors that reduce complications and improve the prognosis of the patients. ${ }^{15}$ The opportunity of having multiple specialists evaluate the patient at the same time makes the system more efficient and improves the times of diagnosis and treatment. The same happens in the case of follow-up visits. In our patients, a limited followup led to an increase in mortality by the malformation itself. Thirty-eight percent of the deaths in our patients were directly related to the malformation. Similar results were seen in complications.

At first impression, the fact that the mothers spend all day taking care of their children might seem like a good thing.
Nonetheless, the problem is when we identify that the most important limitation parents face to access health care is the lack of economic resources to pay for transportation and medical bills. This means that if the mother does not work, the family income will come from a single parent when there is a father taking care of their children. Cases of single mothers are even more critical.

We acknowledge the limitations of our methodology, knowing that we are not evaluating the entire population at risk, but the results of our survey clearly confirm our fears and establish important results to be addressed to improve patient care. Simple measures, like primary care physicians and pediatricians' education might improve the referrals of the patients. Mandatory referrals to transdisciplinary teams supervised by the government would be a simple solution with dramatic reductions in costs to the health system and improvements in the prognosis of the patients.

\section{Conclusion}

Patients born with CAs have a good chance of improving their prognosis and reduce disability. Nonetheless, there are important limitations in the access to appropriate health care. The main barrier is the access to be seen by a specialist and to continue an efficient treatment afterwards.

Conflicts of Interests

The authors have no conflict of interests to declare.

\section{References}

1 Egbe A, Uppu S, Lee S, Stroustrup A, Ho D, Srivastava S. Congenital malformations in the newborn population: a population study and analysis of the effect of sex and prematurity. Pediatr Neonatol 2015;56(01):25-30

2 Carmichael SL. Birth defects epidemiology. Eur J Med Genet 2014; 57(08):355-358

3 Zarante I, Zarante AM, Fernández N. Frecuencia de malformaciones congénitas genitales y urológicas en Colombia Frequency of genito-urinary congenital malformation in Colombia. Rev Argent Urol 2009;74(02):85-90

4 Damen-Elias HAM, De Jong TPVM, Stigter RH, Visser GHA, Stoutenbeek PH. Congenital renal tract anomalies: outcome and 
follow-up of 402 cases detected antenatally between 1986 and 2001. Ultrasound Obstet Gynecol 2005;25(02):134-143

5 Liptak GS, Garver K, Dosa NP. Spina bifida grown up. J Dev Behav Pediatr 2013;34(03):206-215

6 Ewigman BG, Crane JP, Frigoletto FD, LeFevre ML, Bain RP, McNellis D; RADIUS Study Group. Effect of prenatal ultrasound screening on perinatal outcome. N Engl J Med 1993;329(12):821-827

7 García MA, Imbachí L, Hurtado PM, Gracia G, Zarante I. Ultrasound detection of congenital anomalies in 76,155 births in the cities of Bogotá and Cali, 2011-2012. Biomedica 2014;34(03): 379-386

8 Fernández N, Henao-Mejía J, Monterrey P, Pérez J, Zarante I. Association between maternal prenatal vitamin use and congenital abnormalities of the genitourinary tract in a developing country. J Pediatr Urol 2012;8(02):121-126

9 Zarante I, Franco L, López C, Fernández N. Frequencies of congenital malformations: assessment and prognosis of 52,744 births in three cities of Colombia. Biomedica 2010;30 (01):65-71
10 Longpre M, Nguan A, Macneily AE, Afshar K. Prediction of the outcome of antenatally diagnosed hydronephrosis: a multivariable analysis. J Pediatr Urol 2012;8(02):135-139

11 Ravindra Shukla A. Posterior Urethral Valves and Urethral Anomalies. In: Campbell-Walsh Urology. 11th ed. Elsevier; 2016:3252-3271.e3

12 Burke R, Liptak GS; Council on Children with Disabilities. Providing a primary care medical home for children and youth with spina bifida. Pediatrics 2011;128(06):e1645-e1657

13 American Academy of Pediatrics. Timing of elective surgery on the genitalia of male children with particular reference to the risks, benefits, and psychological effects of surgery and anesthesia. Pediatrics 1996;97(04):590-594

14 Lee PA, Nordenström A, Houk CP, et al; Global DSD Update Consortium. Global Disorders of Sex Development Update since 2006: Perceptions, Approach and Care. Horm Res Paediatr 2016; 85(03): $158-180$

15 Hiort O, Birnbaum W, Marshall L, et al. Management of disorders of sex development. Nat Rev Endocrinol 2014;10(09):520-529 